\title{
PRODUÇÃO DE ÁCIDO BUTÍRICO POR CLOSTRIDIUM BUTYRICUM A PARTIR DE GLICERINA
}

\author{
A. S. TAVARES ${ }^{1}$, F. F. MARTINS ${ }^{2}$, M. A. Z. COELHO ${ }^{3}$, T. F. FERREIRA ${ }^{4}$ \\ ${ }^{1}$ Universidade Federal do Rio de Janeiro, Departamento de Engenharia Bioquímica \\ ${ }^{2}$ Universidade Federal do Rio de Janeiro, Departamento de Engenharia Bioquímica \\ ${ }^{3}$ Universidade Federal do Rio de Janeiro, Departamento de Engenharia Bioquímica \\ ${ }^{4}$ Instituto Federal do Rio de Janeiro, Campus Rio de Janeiro \\ E-mail para contato: tatiana.ferreira@ifrj.edu.br
}

\begin{abstract}
RESUMO - O ácido butírico, de suma importância para a indústria química e alimentícia, é produzido pela oxidação de butiraldeído por oxosíntese. A bactéria Clostridium butyricum é anaeróbica e metaboliza matéria orgânica, como a glicerina, que é produzida como um subproduto do biodiesel. Nesse sentido, o objetivo do trabalho foi avaliar a síntese de ácido butírico por $C$. butyricum a partir glicerina bruta. As células foram inoculadas em frascos de vidro do tipo SCHOOT $^{\circledR}$, com $200 \mathrm{~mL}$ de meio de cultivo, em agitador rotatório a $37^{\circ} \mathrm{C}$ e $250 \mathrm{rpm}$ por 16 horas. Seguiu-se, então para um biorreator, em condições anaeróbias, a $200 \mathrm{rpm}$ e 30 horas com controle de temperatura e pH. A análise do consumo de glicerol e dos produtos formados foi realizada através da técnica de Cromatografia Líquida de Alta Eficiência (CLAE). Praticamente todo glicerol (15,65 g.L - $^{-}$

${ }^{1}$ ) foi consumido em 6 horas, ocorrendo produção de 1,3-propanodiol (PDO) (16,18 g.L.1 $)$ e de ácido butírico (4,69 g. $\left.\mathrm{L}^{-1}\right)$. Assim, a glicerina mostrou-se um substrato promissor para produção de ácido butírico.
\end{abstract}

\section{INTRODUÇÃO}

O elevado consumo de combustíveis fósseis aliado à crise energética mundial reforçam a procura por alternativas que pudessem suprir a alta demanda do mercado e que estejam dentro dos padrões exigidos pelos órgãos ambientais. Nesse sentido, os bioprocessos encontram-se em destaque, pois utilizam-se de matéria-prima renovável para a obtenção de produtos que já são sintetizados por via química, com pouca formação de co-produtos indesejáveis.

As bactérias do gênero Clostridium são anaeróbicas, metabolizam desde fontes simples de carbono, como $\mathrm{CO}$ e $\mathrm{CO}_{2}$, fontes mais complexas, como carboidratos e gorduras, produzindo intermediários importantes industrialmente, como o 1,3-propanodiol (PDO), dihidróxiacetona, acido succínico, ácido propiônico, ácido cítrico, etanol e biosurfactantes (Jang et al., 2012). As cepas de $C$. butyricum são geralmente reportadas pela produção de PDO a partir de glicerol como substrato. Além disso, o micro-organismo apresenta-se como promissor na síntese de ácido butírico.

O ácido butírico, ou ácido butanóico, está presente na manteiga rançosa e, por isso, é 
responsável pelo odor e sabor característico. Dessa forma, suas aplicações são bastante abrangentes na indústria de laticínios e alimentos em geral. Além disso, exerce um papel importante em materiais plásticos, fibras têxteis e na indústria farmacêutica. Comercialmente, é sintetizado pela oxidação do nbutiraldeído, o qual pode ser obtido pela oxosíntese de olefinas, como o propileno, por exemplo. Entretanto, a rota biotecnológica obtém produtos mais específicos e com maior pureza (Zigová e Sturdik, 2000).

A glicerina, produto industrial que contém pelo menos $95 \%$ de glicerol puro, pode ser utilizada para a síntese de produtos químicos intermediários, por via química ou fermentativa, enquanto que a glicerina bruta, isto é, coproduzida ao biodiesel, contém cerca de $80 \%$ de glicerol puro. A alta produção de biodiesel nos últimos anos gerou uma quantidade elevada de glicerina que o mercado não consegue absorver em sua totalidade. Para cada quilo do biocombustível produzido sobram 100 quilos de glicerol. Somente para este ano estima-se uma produção de 0,5 bilhões de litros e para 20201,4 bilhões de litros de glicerol (Vasconcelos, 2012). Desse modo, novos estudos focam no aproveitamento desse resíduo, agregrando-o valor a partir de novas aplicações, principalmente, por rotas sustentáveis.

\section{OBJETIVO}

O objetivo deste trabalho foi avaliar a produção de ácido butírico pela bactéria Clostridium butyricum NCIMB 8082, utilizando glicerina bruta como substrato.

\section{MATERIAIS E MÉTODOS}

\subsection{Micro Organismo}

A bactéria utilizada para estes ensaios foi a Clostridium butyricum NCIMB 8082. Esta cepa foi obtida do National Collection of Industrial and Marine Bacteria (NCIMB), cuja ativação foi feita utilizando Meio Fluido de Tioglicolato e Reinforced Clostridia Medium.

\subsection{Preparo do Inóculo}

A cultura de células foi mantida em frascos de penicilina a $4{ }^{\circ} \mathrm{C}$ contendo $50 \mathrm{~mL}$ de Reinforced Clostrida Medium. Estes frascos, contendo células crescidas, foram incubados em agitador rotatório a $37^{\circ} \mathrm{C}$ e $250 \mathrm{rpm}$ por 30 minutos. Em seguida, as células foram inoculadas em frascos de vidro do tipo $\mathrm{SCHOTT}^{\circledR}$, contendo $200 \mathrm{~mL}$ do meio de cultivo, a $37{ }^{\circ} \mathrm{C}$ por 16 horas em agitador rotatório a 250 rpm. O meio de cultivo utilizado tanto para esta etapa quanto para a fermentação é descrito na Tabela 1 .

\subsection{Fermentação}

O meio de cultura contido nos frascos SCHOTT foram totalmente transferidos para um biorreator contendo $800 \mathrm{~mL}$ do meio de cultivo, purgando $\mathrm{N}_{2}$. $\mathrm{O}$ glicerol bruto, utilizado como substrato, foi obtido a partir de uma planta piloto de biodiesel de Petróleo Brasileiro S.A. 


\section{(PETROBRAS).}

Tabela 1. Meio de Cultivo (Chatzifragkou et al., 2011)

\begin{tabular}{cc}
\hline Composto & Concentração $\left(\mathrm{g} . \mathrm{L}^{-1}\right)$ \\
\hline $\mathrm{K}_{2} \mathrm{HPO}_{4}$ & 3,4 \\
$\mathrm{KH}_{2} \mathrm{PO}_{4}$ & 1,3 \\
$\left(\mathrm{NH}_{4}\right)_{2} \mathrm{SO}_{4}$ & 2,0 \\
$\mathrm{MgSO}_{4} \cdot 7 \mathrm{H}_{2} \mathrm{O}$ & 0,2 \\
$\mathrm{CaCl}_{2} \cdot 2 \mathrm{H}_{2} \mathrm{O}$ & 0,02 \\
$\mathrm{CaCO}_{3}$ & 2,0 \\
Extrato de Levedura & 1,0 \\
Glicerina & 20,0 \\
Solução Traço & $2,0\left(\mathrm{ml} \cdot \mathrm{L}^{-1}\right)$ \\
Solução de Fe & $1,0\left(\mathrm{ml} \cdot \mathrm{L}^{-1}\right)$ \\
pH & 7,0 \\
\hline
\end{tabular}

O ensaio foi desenvolvido em condições anaeróbicas em biorreator com capacidade útil de $1 \mathrm{~L}$ a $37^{\circ} \mathrm{C}, 200 \mathrm{rpm}$ por 30 horas com controle de temperatura e $\mathrm{pH}$ durante o dia. $\mathrm{O}$ meio de alimentação foi composto de glicerol $\left(200\right.$ g.. - $\left.^{-1}\right)$ e extrato de levedura $\left(10\right.$ g.. . $\left.^{-1}\right)$.

\subsection{Análises}

A partir do biorreator de $1 \mathrm{~L}$ foram retiradas amostras em diferentes tempos para a análise do consumo de glicerol, dos produtos formados e do crescimento celular. Para quantificar o consumo de glicerol foram realizadas análises por Cromatografia Líquida de Alta Eficiência (Waters®), utilizando coluna Aminex ${ }^{\circledR}$ HPX-87H Ion Exclusion de dimensões $300 \mathrm{~nm}$ x 7,8 nm (Bio-Rad Laboratories), detector de índice de refração RID-10A (Shimadzu), bomba LC-20ADSP (Shimadzu) e software cromatográfico: LabSolutions (Shimadzu). A fase móvel utilizada foi H2SO4 $5 \mathrm{mM}$ com vazão de 0,8 $\mathrm{mL} / \mathrm{min}$, o volume de injeção foi $20 \mu \mathrm{L}$ e a temperatura da corrida $60^{\circ} \mathrm{C}$. Os padrões (Sigma-Aldrich) de todos os analitos estudados foram diluídos em água Mili-Q e injetados em triplicata para preparação da curva padrão, que relaciona a área obtida no cromatograma com a concentração do composto. As amostras foram filtradas em membrana (CHROMAFIL ${ }^{\circledR}$ ) com diâmetro de $0,45 \mu \mathrm{m}$ e injetadas em duplicata para a quantificação através do uso da curva padrão.

${ }^{1}$ Solução Traço: $70 \mathrm{mg} \mathrm{ZnC12,} 0.1 \mathrm{~g} \mathrm{MnCl2} \cdot 4 \mathrm{H} 2 \mathrm{O}, 60 \mathrm{mg} \mathrm{H} 3 \mathrm{BO} 3,0.2 \mathrm{~g} \mathrm{CoC12} \cdot 2 \mathrm{H} 2 \mathrm{O}, 20 \mathrm{mg} \mathrm{CuC12} \cdot 2 \mathrm{H} 2 \mathrm{O}, 25$ mg NiC12·6H2O, $35 \mathrm{mg} \mathrm{Na} 2 \mathrm{MoO} 4 \cdot 2 \mathrm{H} 2 \mathrm{O}, 0.9 \mathrm{~mL} \mathrm{HC} 1$ (37\%). 


\section{RESULTADOS E DISCUSSÃO}

Na Tabela 2 são mostradas as concentrações dos produtos obtidos a partir dos resultados gerados pela Cromatografia Líquida de Alta Eficiência (CLAE). A fase em batelada seguiu até 7 (sete) horas de experimento. Em seguida, realizou-se a alimentação em 7 (sete) horas e meia de fermentação.

Pode-se observar que houve consumo de praticamente todo o glicerol inicial em 6 (seis) horas de fermentação, mostrando que a glicerina bruta é um substrato de fácil assimilação para cepa que está sendo estudada. Ao mesmo tempo, houve produção de ácido butírico e de 1,3-propanodiol (PDO), sendo este último o mais produzido.

\section{Avaliação do Consumo de Glicerol e da Produção de PDO e Ácido Butírico}

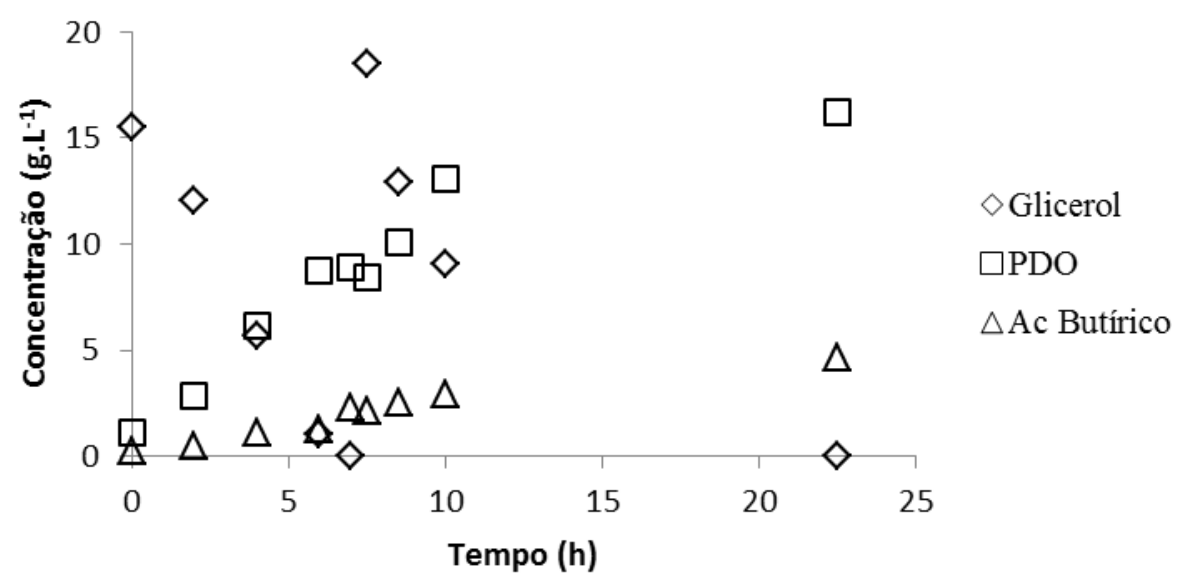

Figura 1. Concentração de Glicerol, Ácido Butírico e de PDO na fermentação de glicerina bruta utilizando Clostridium butyricum NCIMB 8082.

Nas 10 primeiras horas de fermentação, o pH foi mantido entre 6,0 e 7,0, o que favoreceu a produção de PDO, atingindo 13,03 g. $\mathrm{L}^{-1}$, enquanto obteve-se 2,90 g.L $\mathrm{L}^{-1}$ de acido butírico. Todavia, após às 10 horas desligou-se o controle de $\mathrm{pH}$, sendo assim o pH foi reduzindo e ficou entre 5,5 e 6,0, o que deslocou a via para a produção ácido butírico, atingindo a produção máxima de 4,69 g.L $\mathrm{L}^{-1}$.

A Tabela 3 mostra o rendimento e a produtividade de ácido butírico e de PDO obtidos na fermentação realizada. Os cálculos de rendimento e produtividade foram realizados separadamente para as duas fases: a fase com controle de $\mathrm{pH}$, que corresponde as 10 primeiras horas de fermentação, e a fase sem controle de $\mathrm{pH}$, após 10 horas de fermentação. Nota-se uma diferença significativa de rendimento e produtividade quando o pH é alterado. Ao se mantê-lo a concentração de PDO é bem mais alta que a do ácido, entretanto, ao reduzí-lo, é obtido um aumento relevante em apenas 3 horas 
de diferença, apesar de o ganho de diol ter se mantido. É possível que a redução do pH tenha favorecido a produção rápida do ácido, embora de valor ainda baixo.

Tabela 3. Rendimento de glicerol em ácido butírico e $\mathrm{PDO}\left(\mathrm{Y}_{\mathrm{P} / \mathrm{S}}\right)$ e produtividade $(\mathrm{Q})$ dos principais produtos obtidos para as duas fases: com controle de $\mathrm{pH}$ e sem controle de $\mathrm{pH}$.

\begin{tabular}{ccccc}
\hline & \multicolumn{2}{c}{ Com controle de $\mathrm{pH}$} & \multicolumn{2}{c}{ Sem controle de $\mathrm{pH}$} \\
\hline & $\mathrm{Y}_{\mathrm{P} / \mathrm{S}}\left(\mathrm{g} \cdot \mathrm{g}^{-1}\right)$ & $\mathrm{Q}\left(\mathrm{g} \cdot \mathrm{L}^{-1} \cdot \mathrm{h}^{-1}\right)$ & $\mathrm{Y}_{\mathrm{P} / \mathrm{S}}\left(\mathrm{g} \cdot \mathrm{g}^{-1}\right)$ & $\mathrm{Q}\left(\mathrm{g} \cdot \mathrm{L}^{-1} \cdot \mathrm{h}^{-1}\right)$ \\
\hline Ácido Butírico & 0,12 & 0,29 & 0,20 & 0,60 \\
PDO & 0,52 & 1,30 & 0,35 & 1,05 \\
\hline
\end{tabular}

Resultados semelhantes são observados na literatura para a fermentação de Clostridium butyricum. Zigová et al. (1999) reportaram que foram encontrados $0.19 \mathrm{~g}$ butirato/g açúcar e 0.23 g.L. ${ }^{1} \cdot \mathrm{h}^{-1}$ de ácido butírico quando sacarose foi usada como fonte de carbono em batelada, com pH 5,2 e ajustado apenas no início. No mesmo trabalho, foram encontrados $0,30 \mathrm{~g}$ butirato/g açúcar e $0,21 \mathrm{~g} . \mathrm{L}^{-}$ ${ }^{1} \cdot \mathrm{h}^{-1}$ com o mesmo substrato, porém com alimentação e $\mathrm{pH}$ mantido em 5,2 . Isso porque, de acordo com os autores, em baixos valores de $\mathrm{pH}$ a fase solventogênica da via metabólica é favorecida e, com isso, pois aumentou a quantidade deste ácido produzida. Por outro lado, quando em fermentação contínua, com 30 g. $\mathrm{L}^{-1}$ de glicerol e pH mantido em 7,0, 4,4 g.L $\mathrm{L}^{-1}$ de ácido butanóico e $0.15 \mathrm{~g}$ butirato/g glicerol foram reportados por Papanikolaou et al. (2000), além de 16,5 g.L $\mathrm{L}^{-1}$ de PDO e 0,55 g PDO/g glicerol. Esses resultados foram explicados pelo fato de o $\mathrm{pH}$ neutro favorecer a via de produção de 1,3-propanodiol, enquanto que taxas de diluição crecentes do meio direcionam para um aumento da produção de ácido butírico.

Esses dados mostram que a cepa utilizada é promissora, uma vez que são bem próximos aos relatados de ácido butírico e de PDO. Este glicol é de suma importância para a síntese de poliésteres, poliuretanos e para a indústria farmacêutica (Papanikolaou et al., 2000). Os resultados obtidos são bastantes atrativos, já que o 1,3-propanodiol não é mais produzido por via sintética e sim por rota biotecnológica. Dessa forma, é evidenciado o potencial da glicerina como substrato para as bactérias do gênero Clostridium.

\section{CONCLUSÃO}

O uso da glicerina como fonte de carbono na fermentação de C. butyricum mostrou ser muito promissora. As concentrações, os rendimentos e as produtividades obtidos para o 1,3-propanodiol e o ácido butírico são relevantes e competitivos quando comparados com os dados relatados na literatura, principalmente, quando se leva em consideração a influência do pH.

Com isso, a produção de ácido butírico por essa cepa agrega valor não somente à via metabólica de sua produção, como também à de PDO e, principalmente, por utilizar uma matéria-prima de baixo custo em relação aos produtos gerados. 


\section{AGRADECIMENTOS}

Agradecimentos à ANP, Agência Nacional do Petróleo, Gás Natural e Biocombustíveis, pelo fomento à pesquisa.

\section{REFERÊNCIAS}

CHATZIFRAGKOU, A.; PAPANIKOLAOU, S.; DIETZ, D; DOULGERAKI, A.I.; NYCHAS, G.-J; ZANG, A.-P. Production of 1,3-propanediol by Clostridium butyricum growing on biodieselderived crude glycerol through a non-sterilized fermentation process. 91 (1), 101-112, 2011.

Jang, Yu-Sin; Malaviya, A.; Cho, C.; Lee, J.; Lee, S.Y. Butanol production from renewable biomass by clostridia. Biores. Tech., 123, 653-633, 2012.

MOTA, C.J.A.; SILVA, C.X.A.; GONÇALVES, V.L.C. Gliceroquímica: Novos produtos e processos a partir da glicerina de produção de biodiesel. Quím. Nova, 32, 639-648, 2009.

PAPANIKOLAOU, S.; RUIZ-SANCHEZ, P.; PARISET, B.; BLANCHARD, F.; FICK, M. High production of 1,3-propanediol from industrial glicerol by a newly isolated Clostridium butyricum strain. J. Biotech., 77, 191-208, 2000.

VASCONCELOS, Y. Glicerina, resíduo bem-vindo do biodiesel e as pesquisas em destaque. Disponível em: <http://www.biodieselbr.com/noticias/usinas/glicerina/glicerina-residuobiodiesel-pesquisas-040712.htm >. Acesso em: 28 de Abr. 2014.

ZIGOVA, J; STURDIK, E. Advances in biotechnological production of butyric acid. J. Ind. Microb. Biotech., 24, 153-160, 2000.

ZIGOVA, J; STURDIK, E; VANDAK, D; SCHLOSSER, S. Butyric acid production by Clostridium butyricum with integrated extraction and pertraction. Proc. Biochem., 34, 835-843, 1999. 